\title{
K-12 Pedagogical Tunable Modules
}

\section{Andres Cornel Chavez, California State University Northridge}

Andres C. Chavez was born November 24, 1989 in Panorama City, CA. As an undergraduate he attended California State University Northridge (CSUN) where he double majored in Mechanical Engineering and Mathematics and graduated with a Bachelor of Science degree in May 2012. Currently, Andres is pursuing a Master's degree in Mechanical Engineering at CSUN where his research focus is on smart materials and engineering education. A design stemming from his educational research has been field tested and should be implemented in local school curricula in the near future. Andres plans to continue his education by pursuing doctoral studies in Mechanical Engineering with an emphasis in Solid Mechanics and conducting research in smart material systems.

\section{Stephanie Marie Jaco, California State University Northridge Alejandro Roldan, California State University Northridge Matthew Ferrer, CSUN \\ Miss Joyceanne Sim \\ Dr. George Youssef, California State University, Northridge}

Dr. George Youssef is an Assistant Professor at California State University, Northridge. His research interest is in the area of experimental mechanics and biomechanics. He recently was recognized by Engineers Council as Distinguished Engineering Educator for 2014. Dr. Youssef has many publications on the mechanics of polyurea. He earned his Ph.D. from University of California, Los Angeles, in 2010. 


\section{K-12 Pedagogical Tunable Modules (K-12 and Pre-College Engineering)}

Mechanical Engineering Department, California State University Northridge, Northridge, CA

\section{Abstract}

K-12 students are rarely engaged in out of the classroom scientific activities. These activities however, tend to emphasize the learning of the fundamental science, i.e. mathematics and physics, rather than practical and core engineering skills such as design, system integration and troubleshooting. This is also apparent in current K-12 curricula which lack hands-on engineering concepts due to time and resource constraints imposed on science educators by administrators and state standards. The cumulative effect of these approaches to education over a student's precollege academic lifetime results in: 1) a shortage in career-ready high school graduates; and 2) a limited number of college bound students pursuing STEM education and careers. Moreover, those graduates who seek STEM education may have strong analytical skills, but lack the critical thinking, hands-on and practical skills needed for scientific applications, i.e. engineering or experimentation. This serious problem is further elevated by the sporadic availability of financial support to develop and disseminate engineering-based outreach activities. This combined effect severely hinders the quality and number of domestic scientists and engineers produced by the U.S., thus inhibiting the country's competitiveness in the global economy's technology sector. In order to address this issue, the concept and a functional prototype of a tunable educational module has been developed. The uniqueness of this approach follows from the module's capability of modifying a single engineering activity to meet time and student skill-level restraints as well as the mentors' or teachers' time and effort constraints; i.e., tunability.

A module was developed in order to implement and test the concept of tunability. In particular, the module focuses on an electric bell, which was chosen due to its simplicity and its broad as well as fundamental underlying physics and engineering skills. It can be taught on several levels; e.g. basic principles such as polarity (elementary school students) up to using the Biot-Savart law (high school or community college students). The module provides a lesson plan for instructors or mentors, clearly defined objectives and outcomes, and methods for evaluating its effectiveness (e.g. surveys and worksheets). It consists of a "core" set of topics (e.g., electromagnets, polarity and magnetic fields) and a set of "blocks" (e.g., EM assembly and Ampere's law), which can be added to the core to tune the intricacy. These blocks increase the level of details, and thus difficulty, of each lesson by incorporating deeper levels of physics, mathematics, and assembly/experimentation (e.g., deriving the flux of a solenoid or taking voltage measurements of the battery for field calculations). A functional prototype and complete lesson plan were presented to two groups of high school students from different schools as an outreach activity, which was limited to 30 minutes due to the time constraints set by the school administrators. The majority of the participants were reported to be from underrepresented minority groups. The impact of the developed module on the students' interest as well as the effect of their prior knowledge on the completion of module activities are presented.

Introduction and background

It is known that engineers need to possess strong visualization and problem solving skills, yet the K-12 education system fails to implement visualization and practical problem solving lessons 
into the curriculum thereby decreasing interest in engineering and science. This problem is further compounded by the lack of hands-on extra-curricular activities that spark interest in science and engineering while improving the troubleshooting and practical skills of the students. In fact, our young generations are mastering the usage of keyboards, mice, and touchscreens more than their predecessors with disregard to machine shops skills, drafting or even home fixing projects. It is important to note that K-12 science educators are capable and well-trained to deliver all the desired skill sets listed above, however they are asked to prepare students for exams rather than ensure the development life-long learning skills. Often they are required to do so with very limited resources. The results are shortcomings evident in college students who either lack an overall interest in engineering and science or simply do not have the required skills to compete and become successful in today's global and technologically-advanced marketplace. In turn, this can be considered as a threat to national growth and competitiveness in both the economic and defense sectors, which eventually will impact the quality of life of all Americans. By further observation of the K-12 education system, one can note a continuous focus on: 1) abstract knowledge that disinterests students in STEM due to the lack of practicality and/or relevance to their daily lives; 2) theoretical knowledge rather than design, hands-on, and engaging activities; and 3) supplementing continuously shrinking budgets which negatively impact encounter time and development of in-class and extra-curricular activities. The latter is especially true in low socioeconomic schools and school districts.

In this paper, we present a methodology of creating and implementing education modules that can be adopted in-class or as extra-curricular activities. The developed modules attempt to limit the abstraction of knowledge by relating fundamental science concepts to objects, devices or equipment that students encounter on a daily basis. Additionally, the modules relay the theoretical knowledge in a fun and engaging way, where the students must assemble and, in some cases, troubleshoot the modules to achieve proper functionality. Finally, the modules can be used in different grade levels, academic settings, and with varying difficulty and time commitment as deemed suitable by the educator. In general, these educational modules are tunable in knowledge level, time commitment, and student's involvement, which make them suitable for addressing the visualization and problem solving issues of the K-12 curricula at relatively low cost. The reported module is divided into three sections: the lesson plan, the hands-on activity, and finally assessment and evaluation. In what follows, a literature review of similar work and the impact of such activities on the quality of education is first presented. A detailed description of a model educational module is discussed and finally results from a case study as well as discussion of these results are reported. The module reported herein is independent of any specific state science standards to prompt greater adoptability and avoid setting any constrains on the applicability of the developed concepts. That is the module can be used to complement and prompt formal (i.e., in class discussion) or informal education (i.e., outreach activities), respectively.

Brophy et al. discussed the shortage of students interested in STEM education and careers focusing on the shortage of minorities and women in such disciplines ${ }^{1}$. They attributed this shortage to the lack of emphasis on the Engineering aspects in STEM (i.e., "E" in STEM) in the K-12 educational system, which causes the students (especially women) to lose interest because they do not find the learning contexts inviting ${ }^{1}$. They advocated for more hands-on design activities and praised existing programs such as Engineering is Elementary (EiE), LEGO 
Engineering, Project Lead the Way, and the Infinity Project ${ }^{1}$, which focus on introducing K-12 students to engineering early in their education. Prior to Brophy et al., Felder et al. and Feisel et al. outlined deficiencies in current engineering curricula in general stating that much of modern courses focus on abstraction lacking emphasis on application ${ }^{2,3}$. In other words, a continuation of the same unsuccessful approach to science similar to that in K-12 curricula will continue to discourage and disinterest students in STEM. They proposed more hands-on, engaging, and active learning methodologies to increase students' interest and ability ${ }^{2}$. One methodology of creating hands-on, engaging and fun lessons is educational modules to be integrated in the curriculum. The idea of implementing engineering and science modules into outreach activities has been previously reported by Almaguer et al. ${ }^{4}$. They presented a management structure and mission statement for enlisting undergraduate and graduate students in outreach activities for K12 after school programs with specific focus on elementary school students ${ }^{1}$. The Almaguer et al. paper was the seed for the Building Engineers And Mentors (BEAM) student organization and club at the University of California Berkeley, which since then has been duplicated at the University of California Los Angeles and other universities around California in collaboration with local schools and school districts. The approach of using fun and engaging learning activities in after school outreach programs as outlined by Almaguer et al. was confirmed by Dawson et al. to be very effective in helping students to gain greater depth and long term memory of the concepts learned ${ }^{4,5}$. Thus, the educational modules approach was adopted by the current research team to engage and motivate K-12 students in STEM.

The modules presented herein are unique compared to approaches discussed by Almaguer et al. and others ${ }^{4}$ because of their tunability. A tunable educational module is an educational activity that focuses on a single scientific concept or a platform whereby the lesson and accompanying activity can be adjusted to meet student skill-level constraints as well as time requirements. In other words, tunability allows for the adaptation of an activity to fit the skill level of students at different academic levels from elementary school up to undergraduates. Focusing the activity on a product, component, or device that is familiar to all students will help develop interest in STEM. A tunable education module consists of three main components: theoretical introduction, hands-on activity, and assessment/evaluation. For the theoretical introduction, the teacher or mentor finds all the background materials on the scientific concept of choice in a lesson plan packet accompanied by illustrations as well as a discussion about the applicability of the concept in daily life. While developing a tunable module, it is essential that the developed lesson plans are self-contained, integrating broad concepts as well as intricate details pertaining to the covered STEM topic to save time and effort for the educators (e.g., mentors or teachers) thus ensuring successful adoption of the module. The conceptual details are divided into blocks, or rather submodules, to facilitate the tuning of intensity based on the availability of time and effort for both students and teachers. This is illustrated by a case study in the next section. The second component of a tunable module is the hands-on activity, which is necessary to excite the students and capture their attention. In the activity, mentees, i.e. students from a specific K-12 academic level, will design, assemble, test and troubleshoot a platform or a device. Finally, the assessment and evaluation of the impact of the modules are done through worksheets containing questions based on the topics discussed and surveys, which gather information on demographics, interest level, and STEM preparation. An example of a tunable educational module is presented next. 
Electric bell tunable education module

In order to test and prove the strength of the tunable module concept, a module centered on the operation of an electric bell was created. The bell was chosen because of its simplicity and rich underlying physics as well as its relevance to everyday experience as the students encounter them in classrooms daily, e.g. fire alarm bells. The appeal for an activity to teach students about electricity and magnetism (E\&M) stemmed from observations that students are introduced to E\&M in only a few instances throughout their academic careers despite the fact that electromagnetic devices are ubiquitous in our daily lives. Additionally, a plethora of modern technology relies on the coupling of electricity and magnetism, e.g. Smart Phone antennas, automotive window motors, and memory devices. This in turn provides a foundation for students to further explore modern technologies and pique their interest. Figure 1a displays the bell circuit schematic, which will be provided to students to illustrate the path of electricity and how an electromagnet (EM) works within the assembly. The bell assembly (Figures $1 \mathrm{~b}$ and 1c) begins as a short circuit until the momentary switch is turned on to complete the circuit. The battery provides electrical current that travels through the wire into the coils thus magnetizing the EM. Once the EM is temporarily magnetized, the hammer is then attracted to the EM and simultaneously strikes the bell. Once the hammer has made contact with the EM, the circuit is then opened due to the discontinuity between the bell and metallic ring, and the EM is no longer magnetized enough to hold the attraction of the hammer, thus the hammer returns to its original position, re-closing the circuit and starting the whole process over again.
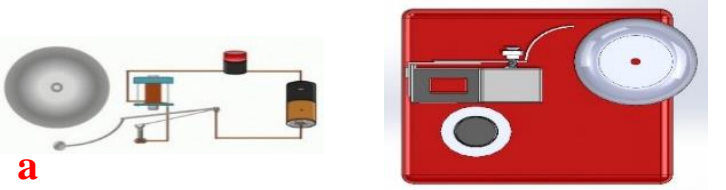

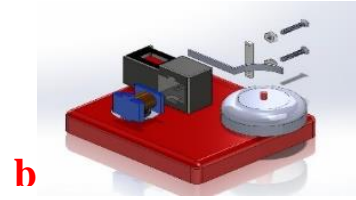

Figure 1: Electric bell. (a) Underlying circuit (b) Conception (c) Realization

The current module, i.e. the tunable electric bell module, consists of various lesson plans to teach K-12 students the underlying physics and engineering concepts intrinsic to the bell. The lesson plans also include illustrations to assist in communicating the concepts to various audiences as well as step-by-step instructions on how to assemble the kit. Depending on time constraints, mentors or teachers can include demonstrations such as playing with bar magnets and magnetic filings or constructing a simple electromagnet using a nail, battery, and magnet wire. A list of all the concepts of the electric bell tunable module are included in the Appendix, where matching colored blocks can be taught together as one level or can be mixed with different colored blocks to adjust and tune the complexity, time-intensity, and level of engagement based on time availability and student academic level. In addition to the lesson plans, the bell assembly was originally modeled in a 3D CAD program (SolidWorks) before components were either purchased or manufactured. Several major components of the bell were manufactured using stereolithography (3D Printing), which include the base, electromagnet (EM) holder, and hammer housing. Additionally, custom metal components were machined in-house, which are the hammer, the bell disk, and the iron core of the EM. Copper wires for the EM, a $9 \mathrm{~V}$ battery, and a momentary switch are readily available off-the-shelf components. The final package of the module includes a survey and worksheet to assess and evaluate the effect of the lesson plan on 
the students' interest in STEM as well as the impact of the lesson plan on the students' knowledge.

The aforementioned E\&M module has been implemented twice with high school students: first (group A) with 54 students ranging from freshmen to seniors from public high schools and second (Group B) with 150 seniors from a college bound charter high schools. For each implementation, a time restriction of thirty minutes was enforced. The module was adapted into an activity that involved a short 10-minute PowerPoint mini lecture on essential topics such as magnetization, current induced magnetic fields, open and closed circuits, and polarity followed by 10 minutes of bell assembly culminating in completion of the survey and worksheet. The results presented in the next section is based on the data collected from the above mentioned outreach visits.

\section{Results and Discussion}

While the worksheet and survey were completed by students from the charter high schools (Group B), only the worksheet was completed by the public high school (Group A). The majority of the participants were from underrepresented groups, where more than $90 \%$ of all students reported Hispanic as their ethnicity and $57 \%$ of the students were females. Since, the survey was not instituted in both outreached groups, the results from the survey are presented first then the results from the worksheet are discussed after.

\section{Survey results}

The survey is included in the Appendix, which contains questions to collect information about demographics, student's interest in science and engineering before and after the activities as well as the student's prior experiences. Table I presents results for student interest based on the surveys. The table shows the interest level among males and females both before and after the activity, where 1 signifies little to no interest and 5 designates high interest. The "More Activities" section indicates the number of students that would approach their teachers for more science and engineering related activities after having completed the bell activity.

Table I: Interest level in STEM

\begin{tabular}{|l|c|c|c|c|c|c|c|c|c|c|c|c|}
\hline \multirow{2}{*}{$\begin{array}{l}\text { Interest } \\
\text { level }\end{array}$} & \multicolumn{2}{|c|}{$\mathbf{1}$} & \multicolumn{2}{|c|}{$\mathbf{2}$} & \multicolumn{2}{|c|}{$\mathbf{3}$} & \multicolumn{2}{|c|}{$\mathbf{4}$} & \multicolumn{3}{|c|}{$\mathbf{5}$} & \multicolumn{2}{|c|}{$\begin{array}{c}\text { More } \\
\text { Activities }\end{array}$} \\
\cline { 2 - 16 } & $B$ & $A$ & $B$ & $A$ & $B$ & $A$ & $B$ & $A$ & $B$ & $A$ & $Y e s$ & No \\
\hline Male & 3 & 1 & 3 & 3 & 24 & 26 & 21 & 21 & 10 & 9 & 54 & 11 \\
\hline Female & 7 & 6 & 23 & 17 & 25 & 33 & 15 & 12 & 8 & 3 & 57 & 23 \\
\hline
\end{tabular}

( $B$ refers to before the activity. $A$ refers after the activity)

Although there was some reduction in high interest in both males and females, the overall trend is one of improving interest levels. Table I shows significant shift in interest occurred in the female population. Specifically, there was a significant shift in females from a negative perception of science (interest levels of 2 or 1) to a neutral perception ( 3 or greater). This is important because this supports the assumption that similar activities can have an impact on student interest in STEM. In particular, such shifts would possibly generate greater participation levels by underrepresented groups (e.g., women) in STEM. This outcome is consistent and 
supports the argument of Brophy et al. that increased interactivity and hands-on exercises with focus on objects from the surrounding environment will have a positive impact on attracting more students, especially women, to STEM. Further impact of the bell module on interest level can be seen from the "More Activities" data in Table I. It can be seen that after completing the activity, approximately $75 \%$ of the students surveyed would be interested in approaching their teachers and asking for more science and engineering related activities. It is also important to note that the intensity, complexity, and time engagement of the module was tuned down to fit within a 30 minute time limitation, however the module can be tuned and adjusted to satisfy the interest of the students without adding any additional cost or development time and effort. For example, the module can be turned into a design competition, where students will be required to create the entire assembly rather than just perform simple wire connections and troubleshooting, e.g., another aspect of tunability. Finally, it is clear that the development and implementation of more tunable educational modules will help in increasing the students' interest and may impact their decision to pursue STEM education and career, while reducing the financial and development burden on educators.

As discussed before, the educational approach to teach science is focused on abstraction instead of practicality, which has a negative impact on students' interest in science and does not inculcate the required skills for successful STEM education and careers. Table II indicates that the majority of the students were not exposed to physics or circuits prior to participating in the electric bell module activity, yet a larger percentage of this population was able to complete the activity in $15 \mathrm{~min}$ or less in comparison to the populations with prior physics or circuit experience. For example, $55 \%$ of students that took a physics course did not complete the activity whereas only $20 \%$ of students that had not taken any physics courses were not able to complete the activity. Similarly, $40 \%$ of students with prior electric circuit experience did not complete the activity whereas only $17 \%$ of students without prior experience did not complete the activity. These results indicate that the teaching paradigm shift embedded in the tunable educational modules can supplement traditional physics and circuit classes with the promise of greater appreciation of the knowledge attained.

Table II: Activity completion based on prior experience

\begin{tabular}{|l|c|c|c|c|}
\cline { 2 - 5 } \multicolumn{1}{c|}{} & \multicolumn{2}{c|}{ Complete } & \multicolumn{2}{c|}{ Did not Complete } \\
\hline Experience/Background & Male & Female & Male & Female \\
\hline Physics & 6 & 3 & 3 & 2 \\
\hline No Physics & 43 & 56 & 7 & 17 \\
\hline Circuits & 15 & 6 & 6 & 8 \\
\hline No Circuits & 34 & 52 & 8 & 10 \\
\hline
\end{tabular}

\section{Worksheet results}

The worksheet contains only three questions and is included in the Appendix. The questions were designed to vary in difficulty to measure the student's ability to grasp and apply scientific and mathematical knowledge as well as communication skills and prior experience. Table III shows the number of students that completed each question as well as the level of difficulty of each question, with 5 indicating the most difficult. A total of only104 worksheets were completed from both outreach activities because some participants did not complete the 
worksheet due to a lack of specific instruction or misuse of time allocation by the mentors conducting the outreach activity.

Table III: Summary of worksheet results

\begin{tabular}{|c|c|c|c|c|c|c|}
\hline & & \multirow{2}{*}{ Difficulty } & \multirow{2}{*}{ Notes } & \multicolumn{3}{|c|}{ Stats } \\
\hline & & & & Complete & Partial & No attempt \\
\hline \multicolumn{2}{|c|}{ Q1 } & 1 & $\begin{array}{l}\text { * requires no prior knowledge } \\
\text { * concepts covered in presentation }\end{array}$ & 76 & 0 & 28 \\
\hline \multirow[b]{2}{*}{ Q2 } & a & 2 & * requires algebra background & 75 & 18 & 11 \\
\hline & b & 2.5 & $\begin{array}{l}\text { * requires algebra background } \\
\text { * requires ability to make logical deductions }\end{array}$ & 71 & 15 & 18 \\
\hline \multicolumn{2}{|c|}{ Q3 } & 4 & $\begin{array}{l}\text { * requires no prior knowledge } \\
\text { * concepts covered in presentation } \\
\text { * requires ability to understand core topics } \\
\text { * requires ability to make logical deductions } \\
\text { * requires ability to communicate scientific } \\
\text { ideas }\end{array}$ & 4 & 23 & 77 \\
\hline
\end{tabular}

As shown in Table III, a majority of the students who attempted the worksheet finished the first two questions, however only a few students finished the third question. The latter is attributed generally to the shortage of time since many students spent more than the allocated time in assembly and troubleshooting. It is worth noting that the mentors covered the answer to the third question during the introductory lesson, so a greater completion amount was expected. As these were the first two implementations, it is likely that the module was tuned to a difficulty level not perfectly suited for the 30 minute time limit which was due to the high number of participants, limited number of electric bell kits, and outreach visit time constraints set by the schools. In future outreach activities of similar logistical constraints, a slightly less involved assembly portion may be necessary to ensure complete coverage of the electromagnetic concepts, assembly, troubleshooting, and evaluation processes.

\section{Conclusion}

A tunable educational module was developed and implemented as part of an outreach activity. The module was based on fundamental concepts of electromagnetism, which was motivated by the existence of fire-bells in many K-12 classrooms in order to relate science to the students' immediate surrounding environment in a fun and engaging way. It was illustrated that such a hands-on and interactive module can help increase interest in STEM education which in turn can lead to an increase in college throughput of scientists and engineers. Based on this success two modules are currently in development. One centers on using magnetic nail polish to understand magnetic fields while the other involves the assembly of a Theremin to better understand electronics. Notably, individuals from BEAM as well as a credential student have been involved in the development of the nail polish module. Additionally, the bell module has been critiqued by faculty in the education department of researching university. Finally, it was shown that the way science is taught must change to allow students to relate the abstract concepts to real life examples. This can be accomplished by providing our science educators with more resources to facilitate the integration of more hands-on activities in the curriculum. The Electric Bell module can serve as model to create, develop and implement more tunable educational modules. 


\section{Bibliography}

[1] Almaguer, A. J., et al. "Building Engineers and Mentors: A Model for Student-Led Engineering Outreach." American Society for Engineering Education. American Society for Engineering Education, 2011.

[2] Brophy, Sean, et al. "Advancing engineering education in P-12 classrooms." Journal of Engineering Education 97.3 (2008): 369-387.

[3] Dawson, Anthony, and Matt Hartley. "GAMES FOR SCIENCE AND ENGINEERING EDUCATION." COMMUNICATIONS OF THE ACM (2007).

[4] Feisel, Lyle D., and Albert J. Rosa. "The role of the laboratory in undergraduate engineering education." Journal of Engineering Education 94.1 (2005): 121-130.

[5] Felder, Richard M., et al. "The future of engineering education II. Teaching methods that work." Chemical Engineering Education 34.1 (2000): 26-39.

[6] Mills, Julie E., and David F. Treagust. "Engineering education-Is problem-based or project-based learning the answer?" Australasian Journal of Engineering Education 3 (2003): 2-16. 
Appendix

Assessment worksheet

1. In which diagram is the circuit closed?

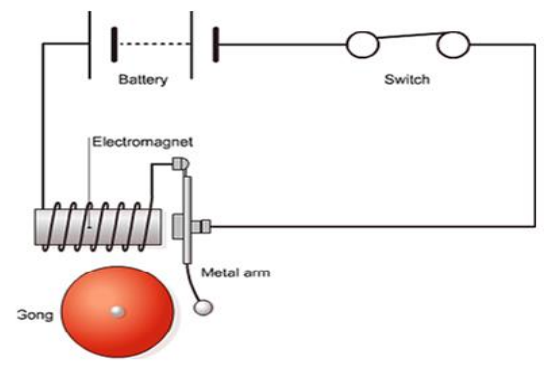

(A)

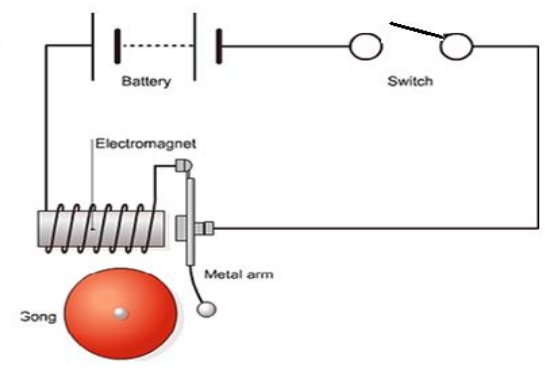

(B)

2. The current in the circuit can be approximated by $i=\frac{V}{R}$, where $V$ is the voltage of the battery and $R$ is the resistance of the wire.

a) If $V=9 \mathrm{~V}$ and the resistance is $100 \Omega$ (ohms). Calculate the current in the circuit. [The unit of current is Amperes denoted by A]

b) The magnetic field strength $(\mathrm{H})$ of the EM coil is given by $H=\frac{N}{L} i$ where $N$ is the number of turns in the coil, $L$ is the length of the wire, and $i$ is the current going through the wire. Find the strength of the magnetic field if $N=200$ turns and $L=7.62 \mathrm{~m}$.

3. Explain how the hammer oscillates. [Hint: what is the interaction between the electromagnet and the hammer?] 
Evaluation survey

1) What is your grade level?
$\square \quad 1-5^{\text {th }}$ grade
$\square-10^{\text {th }}$ grade
$\begin{array}{ll}\square & 6-8^{\text {th }} \text { grade } \\ \square & 11-12^{\text {th }} \text { grade }\end{array}$

2) What school do you attend?

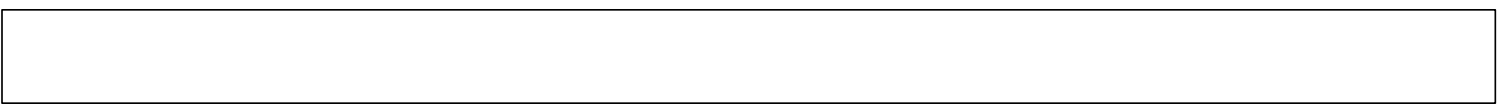

3) Gender:

$\square \quad$ Male

4) Race/Ethnicity:

$\square$ American Indian or Alaska Native

$\square$ Asian

$\square$ White

5) Prior to the activity, I was interested in science and engineering.

$\square$ Strongly disagree $\square$ Disagree $\square$ Undecided $\square$ Agree $\square$ Strongly agree

6) Check all physics courses you have taken.

$\square$ General physics

$\square$ AP Physics 1 (mechanics, work, energy, power; mechanical waves/sound)

$\square$ AP Physics 2 (fluid mechanics; thermodynamics; electricity and magnetism; optics)

$\square$ Has not taken a course in physics

7) Check all mathematics courses you have taken.
$\square$ Arithmetic/General math
$\square$ Pre-Algebra
$\square$ Geometry
$\square$ Pre-calculus
Algebra I
Statistics
$\square$ Algebra II
AP calculus (circle if you have taken any AP Calculus course)
$\square$ Calculus

8) Do you have prior experience building electric circuits?
口 Yes
$\square$ No

9) Was this your first hands on engineering activity?
$\square$ Yes
$\square$ No

10) How long did it take to complete the bell?
口 5-7min
$\square 7-10 \mathrm{~min}$
$\square$ 10-15min
$\square$ never finished

11) The activity was difficult to complete.
$\square$ Strongly disagree
$\square$ Disagree
Undecided
Agree

12) My teammates and I worked well together in building the bell.

$\square$ Strongly disagree $\square$ Disagree $\square$ Undecided $\square$ Agree

13) The worksheet was difficult for me to complete.
$\square$ Strongly disagree
$\square$ Disagree
$\square$ Undecided
Agree
Strongly agree

14) I can communicate the difference between an electromagnet and a permanent magnet. $\square$ Strongly disagree $\square$ Disagree $\square$ Undecided $\square$ Agree $\square$ Strongly agree

15) I will approach my teachers for future activities related to science and engineering. $\square$ Strongly disagree $\square$ Disagree $\square$ Undecided $\square$ Agree $\square$ Strongly agree

16) After the activity I was interested in science and engineering.

$\square$ Strongly disagree $\square$ Disagree $\square$ Undecided $\square$ Agree $\square$ Strongly agree 

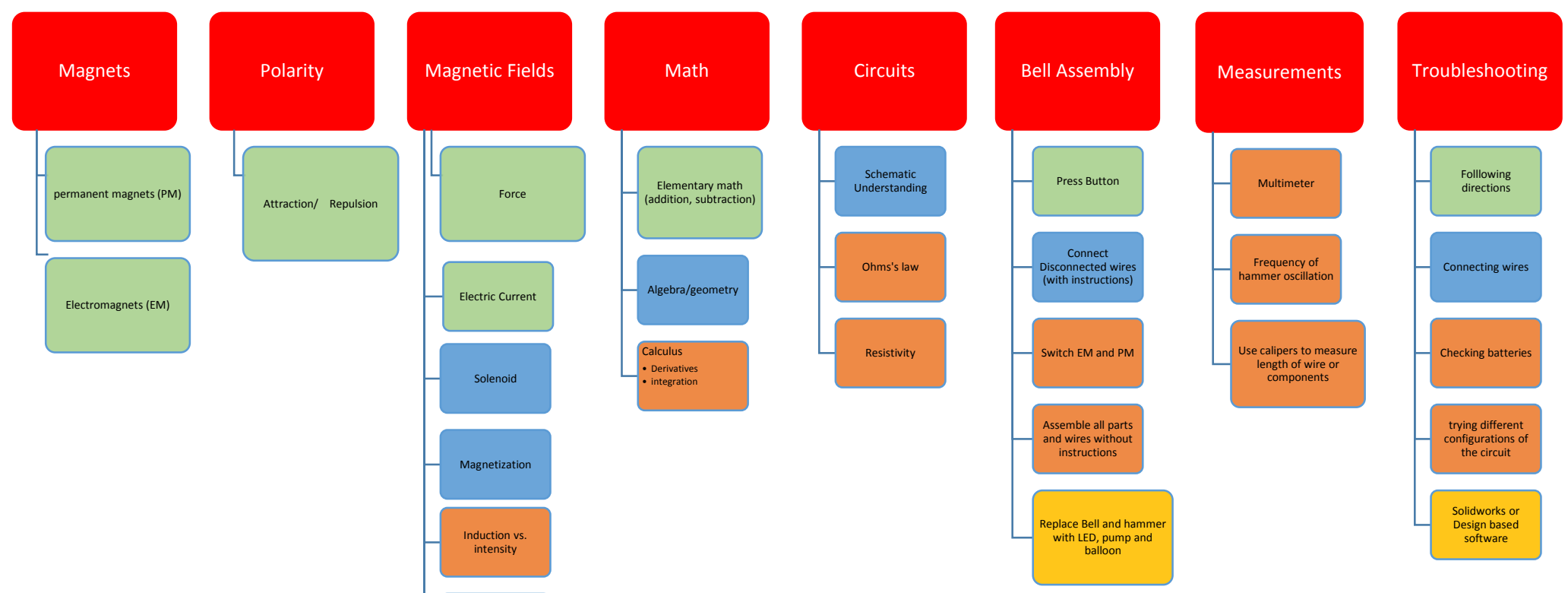

\section{Legend}

Main

Concept

Low Topic

Medium

Topic

High Topic

Superior

Topic

Figure A.1: Concepts covered by electric bell module 